Stitches on Time 



\section{STITCHES ON TIME}

Colonial Textures and Postcolonial Tangles

Saurabh Dube

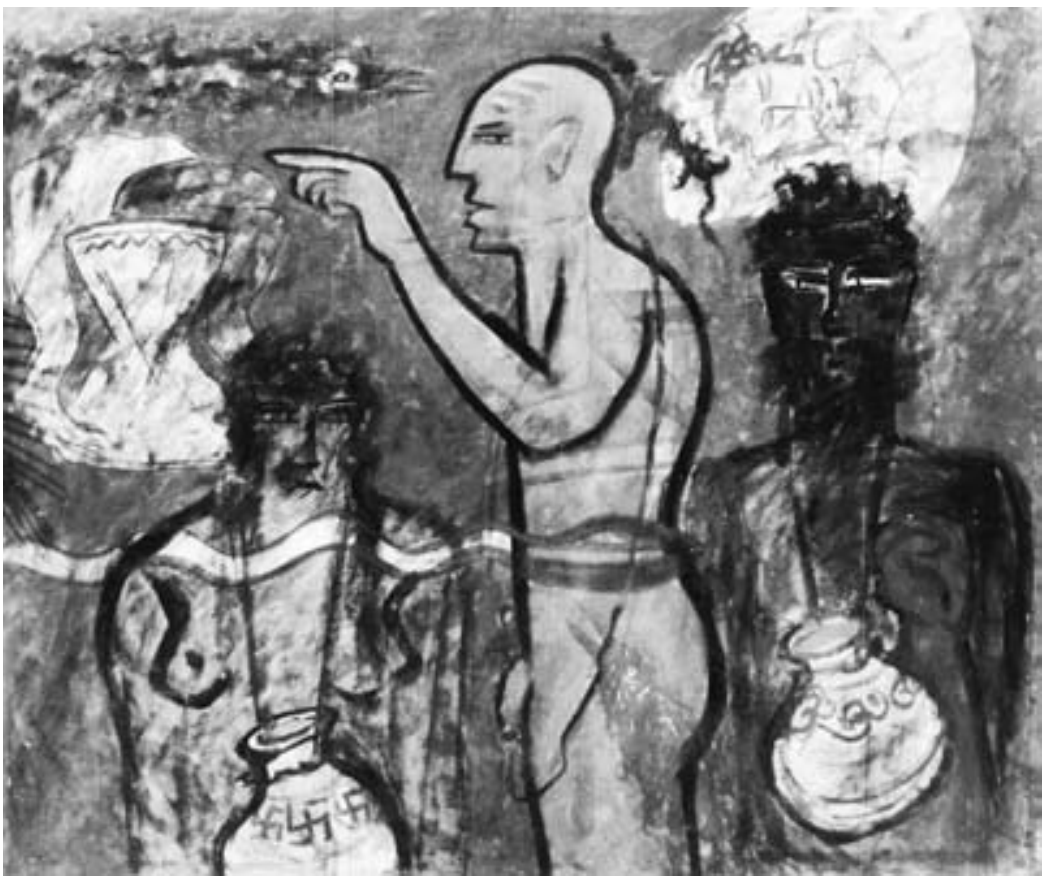

D U K E U N I V E R I T Y P R E S Durham and London 2004 
C2004 Duke University Press

All rights reserved

Printed in the United States of America on acid-free paper $\infty$ Typeset in Quadraat by Keystone Typesetting, Inc.

Library of Congress Cataloging-in-Publication Data appear on the last printed page of this book. 
FOR LEELA DUBE mother and anthropologist 
